\title{
Schizophrenia TreAtment with electRic Transcranial Stimulation (STARTS): design, rationale and objectives of a randomized, double-blinded, sham-controlled trial
}

\author{
Tratamento da esquizofrenia com estimulação transcraniana por corrente contínua \\ (ETCC): fundamentação teórica e objetivos de um ensaio clínico randomizado, \\ duplo-cego, controlado por simulação
}

\begin{abstract}
Leandro Valiengo, ${ }^{1,2,3}$ (D) Pedro Caldana Gordon, ${ }^{2}$ Juliana Barbosa de Carvalho, ${ }^{2}$ Rosa Maria Rios, ${ }^{2}$ Stephanie Koebe, ${ }^{2}$ Mauricio Henrique Serpa, ${ }^{1,3,4}$ Martinus van de Bilt, ${ }^{1,3}$ Acioly Lacerda, ${ }^{5,6}$ Helio Elkis, ${ }^{7}$ Wagner Farid Gattaz, ${ }^{1,3}$ André Russowsky Brunoni ${ }^{1,2,3,7,8}$
\end{abstract}

\begin{abstract}
Introduction: Schizophrenia is a severe mental disorder. While some antipsychotic medications have demonstrated efficacy in treating positive symptoms, there is no widely recognized treatment for negative symptoms, which can cause significant distress and impairment for patients with schizophrenia. Here we describe the rationale and design of the STARTS study (Schizophrenia TreAtment with electRic Transcranial Stimulation), a clinical trial aimed to test the efficacy of a non-pharmacological treatment known as transcranial direct current stimulation (tDCS) for treating the negative symptoms of schizophrenia

Methods: The STARTS study is designed as a randomized, shamcontrolled, double-blinded trial evaluating tDCS for the treatment of the negative symptoms of schizophrenia. One-hundred patients will be enrolled and submitted to 10 tDCS sessions over the left dorsolateral prefrontal cortex (anodal stimulation) and left temporoparietal junction (cathodal stimulation) over 5 consecutive days. Participants will be assessed using clinical and neuropsychological tests before and after the intervention. The primary outcome is change in the Positive and Negative Syndrome Scale (PANSS) negative subscale score over time and across groups. Biological markers, including blood neurotrophins and interleukins, genetic polymorphisms, and motor cortical excitability, will also be assessed.

Results: The clinical results will provide insights about tDCS as a treatment for the negative symptoms of schizophrenia, and the biomarker investigation will contribute towards an improved understanding of the tDCS mechanisms of action.

Conclusion: Our results could introduce a novel therapeutic technique for the negative symptoms of schizophrenia.

Clinical trial registration: ClinicalTrials.gov, NCT02535676.

Keywords: Schizophrenia, electric stimulation therapy, randomized controlled trial, biological markers, transcranial stimulation.
\end{abstract}

\section{Resumo}

Introdução: A esquizofrenia é um transtorno mental grave. Embora alguns medicamentos antipsicóticos tenham demonstrado eficácia no tratamento de sintomas positivos, não há tratamento amplamente reconhecido para sintomas negativos, o que pode causar sofrimento e prejuízo significativos para pacientes com esquizofrenia. Aqui descrevemos a fundamentação teórica e o design do estudo STARTS (Schizophrenia TreAtment with electRic Transcranial Stimulation), um ensaio clínico destinado a testar a eficácia de um tratamento não farmacológico conhecido como estimulação transcraniana por corrente contínua (ETCC) para tratar os sintomas negativos da esquizofrenia.

Métodos: O estudo STARTS foi concebido como um ensaio clínico randomizado, controlado por simulação, duplo-cego, avaliando a ETCC para o tratamento dos sintomas negativos da esquizofrenia. Cem pacientes serão incluídos e submetidos a 10 sessões de ETCC sobre o córtex pré-frontal dorsolateral esquerdo (estimulação anódica) e a junção temporoparietal esquerda (estimulação catodal) durante 5 dias consecutivos. Os participantes serão avaliados através de testes clínicos e neuropsicológicos antes e após a intervenção. O desfecho primário é a mudança na pontuação da subescala negativa da Escala da Síndrome Positiva e Negativa (Positive and Negative Syndrome Scale [PANSS]) ao longo do tempo e entre os grupos. Marcadores biológicos, incluindo neurotrofinas e interleucinas do sangue, polimorfismos genéticos e excitabilidade cortical motora, também serão avaliados.

Resultados: Os resultados clínicos fornecerão informações sobre a ETCC como um tratamento para os sintomas negativos da esquizofrenia, e a investigação dos biomarcadores contribuirá para uma melhor compreensão dos mecanismos de ação da ETCC.

Conclusão: Nossos resultados podem trazer uma nova técnica terapêutica para o tratamento dos sintomas negativos da esquizofrenia.

Registro do ensaio clínico: ClinicalTrials.gov, NCT02535676.

Descritores: Esquizofrenia, terapia de estimulação elétrica, ensaio clínico randomizado, marcadores biológicos, estimulação transcraniana.

\footnotetext{
${ }^{1}$ Laboratório de Neurociências (LIM27), Departamento e Instituto de Psiquiatria, Hospital das Clínicas, Faculdade de Medicina, Universidade de São Paulo (USP), São Paulo, SP, Brazil. ${ }^{2}$ Serviço Interdisciplinar de Neuromodulação (SIN), Departamento e Instituto de Psiquiatria, Hospital das Clínicas, Faculdade de Medicina, USP, São Paulo, SP, Brazil. ${ }^{3}$ Instituto Nacional de Biomarcadores em Neuropsiquiatria (INBioN), Conselho Nacional de Desenvolvimento Científico e Tecnológico (CNPq), Brazil. ${ }^{4}$ Laboratório de Neuroimagem (LIM-21), Departamento e Instituto de Psiquiatria, Hospital das Clínicas, Faculdade de Medicina, USP, São Paulo, SP, Brazil. ${ }^{5}$ Centro de Pesquisa e Ensaios Clínicos Sinapse-Bairral, Instituto Bairral de Psiquiatria, Itapira, SP, Brazil. ${ }^{6}$ Laboratório Interdisciplinar de Neurociências Clínicas (LiNC), Departamento de Psiquiatria, Universidade Federal de São Paulo (UNIFESP), São Paulo, SP, Brazil. 7 Departamento e Instituto de Psiquiatria, Hospital das Clínicas, Faculdade de Medicina, USP, São Paulo, SP, Brazil. ${ }^{8}$ Department and Institute of Psychiatry, LMU Munich, Munich, Germany. Submitted Jul 16 2018, accepted for publication Sep 292018.

Suggested citation: Valiengo L, Gordon PC, de Carvalho JB, Rios RM, Koebe S, Serpa MH, et al. Schizophrenia TreAtment with electRic Transcranial Stimulation (STARTS): design, rationale and objectives of a randomized, double-blinded, sham-controlled trial. Trends Psychiatry Psychother. 2019;41(2):104-111. http:// dx.doi.org/10.1590/2237-6089-2018-0047
} 


\section{Introduction}

Schizophrenia is a severe mental illness that significantly impacts well-being. The negative symptoms of the disorder include blunted affect, apathy, avolition, and anhedonia, and are responsible for a large proportion of the disease burden. These symptoms represent an important clinical challenge, ${ }^{1,2}$ and several studies have associated negative symptoms with lower premorbid functionality, lower IQ, and poorer clinical outcome..$^{3-7}$ Negative symptoms have a clinical course independent from positive symptoms, are stable or increasing in severity over time, and have an independent prognostic weight. $^{3-7}$ Although antipsychotic medications are an effective treatment for positive symptoms and are always recommended for schizophrenia, negative symptoms tend to persist or even worsen in the presence of antipsychotic medication treatment, and no effective treatment for negative symptoms has shown strong supportive evidence. ${ }^{8}$

Evidence for the pathophysiology of negative symptoms points to the involvement of the dorsolateral prefrontal cortex (DLPFC), as neuroimaging studies have shown reduced metabolism in the prefrontal cortex in patients with schizophrenia both with and without medication, ${ }^{9,10}$ along with an inverse correlation between negative symptom severity and cerebral blood flow in the prefrontal cortex. ${ }^{11}$ Hypoactivation of prefrontal regions also seems to be related to the presence of negative symptoms in schizophrenia. ${ }^{12}$ These findings suggest that these areas could be a target for focal interventions by non-invasive brain stimulation, as such stimulation may improve the physiological deficits of the disorder and exert therapeutic effects. Repetitive transcranial magnetic stimulation (rTMS) uses alternating magnetic fields to induce an electric current in cortical tissue ${ }^{13}$ and can change dopamine concentration in prefrontal regions. ${ }^{14}$

rTMS protocols have been investigated as possible treatments for schizophrenia ${ }^{15-26}$; most protocols for negative symptoms have used high frequency stimulation and targeted the DLPFC. However, metaanalyses evaluating the efficacy of rTMS using this approach have shown discordant results. ${ }^{27,28}$ rTMS has also been used to treat auditory hallucinations in schizophrenia, a symptom typically associated with hyperactivity of the left temporoparietal cortex. rTMS protocols designed to inhibit cortical activity in this region have proven generally effective to treat auditory hallucinations. ${ }^{28}$

Transcranial direct current stimulation (tDCS) is another form of non-invasive brain stimulation under research for the treatment of various neuropsychiatric conditions, with encouraging results. ${ }^{29-31}$ This mode of non-invasive brain stimulation has several advantages and could potentially be included as a treatment option for schizophrenia. ${ }^{32}$ tDCS consists of the placement of two electrodes (a cathode and an anode) over the scalp to deliver an electric current of small and constant intensity. The electric current that flows through the cerebral cortex during the tDCS session modifies the electric potential of the extracellular space. As a result, cortical regions close to the anode present a decrease in transmembrane electric potential and an associated increase in neuronal firing rate, while the regions close to the cathode present an increase in transmembrane electric potential and a decrease in neuronal firing rate. ${ }^{33-35}$

tDCS offers some advantages relative to TMS, including 1) portability: tDCS devices are small and portable, allowing for treatment in many different settings, including home treatment, which is especially attractive for patients with limited mobility; 2) duration: the effects of tDCS have longer duration; 3) cost: while the price of an average TMS device varies between 20 and 100,000 U.S. dollars, the cost of a tDCS device ranges between 400 and 10,000 U.S. dollars. ${ }^{36}$

For these reasons, tDCS may represent a promising tool for the treatment of schizophrenia. According to current models of cortical pathophysiology in schizophrenia and the mechanisms of action of tDCS, anodal stimulation of the left DLPFC would generate an increase in activity in this area, leading to an improvement of negative symptoms, while cathodal stimulation of the temporoparietal cortex would decrease cortical activity at the same time, leading to an improvement in hallucinations. This simultaneous excitatory and inhibitory stimulation is possible with tDCS because both the anode and cathode must be placed on the scalp to close the circuit and allow the electric current to pass. A previous study designed to treat auditory hallucinations using this method reported a significant decrease in negative symptoms. ${ }^{37}$ The main aim in this clinical trial is to confirm this hypothesis in a study designed specifically for the treatment of negative symptoms.

The primary objective of this study is to evaluate the efficacy of active tDCS for the treatment of the negative symptoms of schizophrenia, as measured by reduction of the Positive and Negative Syndrome Scale (PANSS) negative symptoms subscale scores 6 weeks after beginning the treatment, relative to sham tDCS.

The secondary objectives are to evaluate:

1) the efficacy of tDCS for the treatment of auditory hallucinations, as measured by the Auditory Hallucination Rating Scale (AHRS); 
2) response rate, defined as a reduction of $\geq 20 \%$ in PANSS negative symptoms subscale scores;

3) efficacy in treating positive symptoms, as measured by the PANSS positive symptoms subscale;

4) efficacy in treating depressive symptoms associated with schizophrenia, as measured by the Calgary Depression Scale for Schizophrenia;

5) change in overall functioning, as measured by the Global Assessment of Functioning (GAF);

6) changes in several blood biomarkers;

7) changes in cognitive measurement.

\section{Methods}

\section{Design and study population}

STARTS is a randomized, double-blinded, placebocontrolled trial. Eligible patients will be recruited from Instituto de Psiquiatria, Hospital das Clínicas, Faculdade de Medicina, Universidade de São Paulo (USP), São Paulo, SP, Brazil, Instituto Bairral de Psiquiatria, Itapira, SP, Brazil, and the primary care services in the respective catchment areas. The study began in September 2014 and plans to enroll 100 participants. Participants who meet the inclusion criteria and agree to participate in the study will be allocated (1:1) into one of two groups, defined as sham or active tDCS. Subjects will receive 10 tDCS sessions over 5 consecutive days. Baseline measurements will be performed before the first session, and follow-up measurements related to the primary outcome will be measured 6 weeks after the first session. Volunteers who do not show an improvement in negative symptoms (defined as a reduction of $\geq 20 \%$ in the negative PANSS score or maintenance of a total negative PANSS score $\geq 20$ points) after having been allocated to the sham group may elect to receive 5 days of active stimulation twice daily (partial cross-over).

\section{Inclusion and exclusion criteria}

This clinical trial was designed to include males and females diagnosed with schizophrenia according to the Diagnostic and Statistical Manual of Mental Disorders, 4th edition (DSM-IV), aged between 18 and 65 years. Potential participants will be screened by a trained psychiatrist to ensure fulfillment of all inclusion criteria. In addition to the PANSS, the Structured Clinical Interview for DSM-IV (SCID) will be applied during the screening interview to confirm the diagnosis of schizophrenia. Patients will only be included if they present a minimum score of 20 points in the sum of the negative symptoms' subscale, are under proper antipsychotic treatment, and have stable positive symptoms. Other drugs that may interfere with the assessment of negative symptoms, including antidepressants, modafinil, erythropoietin, and minocycline will be washed-out for at least 4 weeks before trial onset. Medication type and dosage will be monitored during participation in the clinical trial, and changes in non-psychotropic medication or psychosocial interventions will be allowed.

Exclusion criteria are unstable medical illness, pretreatment with rTMS or tDCS, psychiatric comorbidities (such as mood disorders, personality disorders, abuse or dependence on alcohol or drugs, or use of any illicit drug during the last 6 months), current or previous electroconvulsive therapy during the last 6 months, use of benzodiazepines in doses equal to or higher than $10 \mathrm{mg}$ of diazepam or the equivalent, and the presence of specific contraindications to tDCS such as electronic or metal implants in the cephalic segment. We will include any stage of the disease provided the patient is under stable psychotropic medication and dosage for at least 6 weeks.

Recruitment strategies include a convenience sample of patients with schizophrenia from outpatient and inpatient clinics referred and screened by psychiatrists specialized in psychotic disorders, and spontaneous enrollment through advertisements in local newspapers, radio stations, and websites.

\section{Measurement of variables and outcomes}

Demographic and clinical profiles will be assessed with the following variables: gender, age, years of education, socioeconomic status, medical and psychiatric comorbidities, refractoriness to current psychotic symptoms, duration of current psychotic episode, number of previous hospitalizations for psychotic episodes, and previous treatment with electroconvulsive therapy. Besides, we will assess information regarding predictors of response or refractoriness, e.g.: type and dose of the current antipsychotic drug (in chlorpromazine equivalents), adherence to the current treatment, duration of untreated psychosis and age upon the first episode of schizophrenia.

The primary outcome will be measured with the PANSS negative symptoms subscale. ${ }^{38}$ The PANSS will also be used categorically to separate subjects into responders ( $\geq 20 \%$ reduction in scale) and nonresponders ( $<20 \%$ improvement in scale).

Each participant will be evaluated at baseline, at day 5, week 2, week 4, week 6, and week 12 (Table 1). The PANSS, Auditory Verbal Hallucinations Scale (AVHS), and Calgary Depression Scale for Schizophrenia (CDSS) will be applied at all evaluations and at baseline. We will apply the Scale for Assessment of Negative 
Symptoms (SANS), the Social and Occupational Functional Assessment Scale (SOFAS), and the Clinical Global Impression Scale (CGI), and the participant will complete the World Health Organization Quality of Life instrument-Abbreviated version (WHOQOL-Bref) at baseline and at week 6 . We will use a tDCS questionnaire for adverse effects to assess treatment tolerability. ${ }^{39}$ Blinding efficacy will be assessed at endpoint by asking raters and participants to guess their allocation group.

\section{Randomization and allocation}

Randomization will be generated through the website www.randomization.com and will be performed in blocks to allow permutation of block size and order. Patient allocation will be carried out using sealed, opaque, patterned envelopes, labeled with a random number assigned to the participant. The envelope will be opened and the participant will receive either active or sham treatment according to the code contained in the envelope upon signature of the informed consent form and inclusion in the trial.

\section{Intervention}

A tDCS session involves the placement of two electrodes over the scalp. The anode will be positioned over the area corresponding to the left DLPFC, between F3 and FP1, and the cathode will be positioned over the area of the left temporoparietal junction (CP5). The minimum distance between electrodes is $7 \mathrm{~cm}$, the electrode dimensions are $5 \times 7 \mathrm{~cm}$, and the applied current will be $2 \mathrm{~mA}$. We will use the DC Stimulator tDCS device (Neuroconn (C), IImenau, Germany) in study mode for double-blind trials. Each session will last 20 minutes, and participants will receive two sessions a day over 5 consecutive days (Monday to Friday).

\section{Blinding}

This is a double-blind study: researchers, tDCS technicians, and patients will have no knowledge of the treatment administered to each participant until the end of the study. Technicians will not be allowed to assess the participants.

The tDCS technique is particularly advantageous for ensuring blinding when compared to other noninvasive brain stimulation techniques, as the session provokes only a mild tingling sensation which is habituated in seconds. Given this feature, sham stimulations were designed to deliver only a few seconds of electric current in the beginning of the session and then shut down and provide no electric current for the rest of the session, simulating an active session but providing no clinical or physiological effects. ${ }^{40,41}$

The tDCS device set on study mode requires the technician to enter one of 200 5-digit codes into the device before the session, corresponding to either an active session with parameters as described above, or a sham session. Each participant will be assigned a code according to the intervention group to which they were assigned, found in the randomization envelope. The correspondence between the participant's code and the intervention delivered will remain unknown to the team and the participants, preserving blinding.

\section{Sample size calculation}

Sample size calculation is based on the PANSS negative symptom score, which is the primary outcome of our study. In previous studies, this score has shown an average variation from 20 to 24 points in this type of patient, and a difference of 3 points is considered clinically significant. Standard deviations in previous studies have shown values between 4-5 points. ${ }^{24,38,42}$ Therefore, a study with $80 \%$ power and alpha of 0.05 requires a sample of 44 patients in each group. We expect a dropout rate of $15 \%$, suggesting an enrollment of about 50 patients per group.

\section{Statistical analysis}

Statistical analyses will be performed using Stata 12 SE programs and the Statistical Package for the Social Sciences (SPSS) version 17 for Windows. All analyses

Table 1 - Measurement outcomes over time

\begin{tabular}{|c|c|c|c|c|c|c|}
\hline & Baseline & Week 1 & Week 2 & Week 4 & Week 6 & Week 12 \\
\hline PANSS & $x$ & $x$ & $x$ & $x$ & $x$ & $X$ \\
\hline SANS & $x$ & & & & $x$ & \\
\hline CDSS & $x$ & $x$ & $\mathrm{X}$ & $\mathrm{X}$ & $x$ & $x$ \\
\hline Cognitive test & $x$ & & & & $x$ & \\
\hline Blood sample & $x$ & & & & $x$ & \\
\hline Motor excitability & $x$ & & & & $x$ & $x$ \\
\hline
\end{tabular}

CDSS = Calgary Depression Scale for Schizophrenia; PANSS = Positive and Negative Syndrome Scale; SANS = Scale for Assessment of Negative Symptoms. 
will be performed according to the intention to treat principle (all patients will be included in the analysis).

We will use a general linear model with a continuous dependent variable (PANSS negative symptom score) for the primary outcome measure. Secondary analyses will use the same model, and scores obtained on the other scales will be used as dependent variables. The analyses are considered significant at $p<0.05$.

Exploratory analyses will include other variables potentially influencing the therapeutic effect, including education, number of previous hospitalizations, presence of medical comorbidities, and other socioeconomic variables. Refractoriness to antipsychotic medication will be analyzed as a dichotomous variable, defined as presence or absence of refractoriness.

\section{Cognitive assessments}

The participants will be tested at baseline and at week 6 with the Penn Computerized Neurocognitive Battery (Penn-CNB). The Penn-CNB takes an average of 1 hour to perform and assesses the following domains ${ }^{43}$ : executive control (attention, working memory and abstraction, and mental flexibility), episodic memory (verbal, facial, and spatial), complex cognition (spatial processing), social cognition (emotion discrimination, emotion recognition, and emotional accuracy) and sensory-motor processing (motor praxis and pressing the fingers test).

\section{Biological markers}

Blood samples will be collected from all participants at baseline and at week 6 , and the biomarkers described below will be analyzed. A portion of these samples will be frozen for posterior analysis.

a) Brain-derivedneurotrophicfactor(BDNF):BDNFis a neurotrophin related to synaptic strengthening, neurodevelopment, and neuroprotection, ${ }^{44}$ and has been associated with several psychiatric disorders. BDNF gene polymorphisms are associated with better cognitive performance in patients with schizophrenia. ${ }^{45}$ Another useful approach for studying the role of this biomarker in schizophrenia is the measurement of plasma or serum BDNF levels, as this biomarker can cross the brain-blood barrier. ${ }^{44}$ Blood BDNF levels appear to be lower in patients with chronic schizophrenia compared to controls, ${ }^{46,47}$ and some studies examining BDNF levels before and after treatment found increased levels following the use of antipsychotics. ${ }^{48,49}$ Plasma BDNF levels and BDNF gene polymorphisms will be analyzed with respect to tDCS treatment response.

b) Motor cortical excitability: Studies using TMS-elicited motor evoked potentials have shown alterations in the cortical excitability of patients with schizophrenia, suggesting a global dysfunction of GABAergic activity, in alignment with previous pathophysiological models of schizophrenia. ${ }^{50}$ We will take a series of measurements of cortical excitability using TMSelicited motor evoked potentials following the guidelines for the technique, ${ }^{51}$ both at baseline and during the follow-up evaluation. Our goal is to analyze cortical excitability variables as possible predictors and markers of the clinical outcomes of tDCS treatment for schizophrenia.

c) Other genetic biomarkers: several single nucleotide polymorphisms (SNPs) have been associated with schizophrenia, including GRIA1, ERBB4, DRD2, CACNA1C, and NRG1.52 These SNPs may play a role in the treatment response to tDCS.

\section{Expected results}

Our primary hypothesis is that participants receiving active tDCS will present a reduction of negative symptoms as measured by the PANSS, compared to patients receiving sham tDCS. The results of this study will additionally contribute to the development of further studies on neuromodulation for the treatment of schizophrenia.

\section{Sources of funding}

We receive financial support from Instituto Nacional de Biomarcadores em Neuropsiquiatria (INBioN) for the analysis of biomarkers, and from the Stanley Medical Research Institute for performing the clinical trial.

\section{Computer modelling of tDCS generated electric fields}

We have designed a computer model of the electric field generated by the tDCS montage proposed in this clinical trial. We simulated this electric field using the SimNIBS modelling environment, ${ }^{53}$ which relies on a finite element model of brain current flow based on an magnetic resonance imaging (MRI)-derived template head model. ${ }^{54}$

Electrode disposition in this montage includes the placement of two electrodes with dimensions $5 \times 7 \mathrm{~cm}$ over the participant's scalp, with the anode centered above F3 (10-10 EEG International System) and the cathode centered above CP5, delivering an electric current of $2 \mathrm{~mA}$. A depiction of the montage is provided in Figure 1.

The model predicts a diffuse electric field spreading from the left frontal lobe to the left temporoparietal cortex, reaching maximum intensity in the cortical 
area around the central sulcus. An image of the results yielded by the simulation is presented in Figure 2 .

Similar results were found previously using the same montage, and despite the high intensity of the electric field in a region without clinical interest between the electrodes (primary motor cortex and primary somatosensory cortex), the predicted intensity of the electric field in the regions of interest (the DLPFC and temporoparietal junction) was considered satisfactory for possible clinical trials investigating the treatment of schizophrenia symptoms. ${ }^{53-55}$

\section{Discussion}

The STARTS study will be one of the largest trials to date assessing the efficacy of tDCS for the treatment of schizophrenia. Our protocol consists of 10 sessions of
tDCS using $2 \mathrm{~mA}$ for $20 \mathrm{~min}$, with two sessions a day, similar to the protocol used by Brunelin et al. ${ }^{56}$ Sample size was calculated to avoid type I and II errors and can accommodate an attrition rate of $15 \%$. We will enroll patients with different degrees of refractoriness and variable antipsychotic medication treatments, which will significantly increase the external validity of our results. These data could contribute to the analysis of some predictors of response as well.

This trial differs from the clinical trial conducted by Brunelin et al. in several ways, including a larger sample size (100 vs. 30). We are also collecting blood samples and evaluating several additional parameters and biomarkers related to genetics, neuropsychological state, and motor excitability. We will assess depressive symptoms, medication use, and other possible variables that may influence the results, and we are using multiple scales to assess the negative symptoms (SANS).

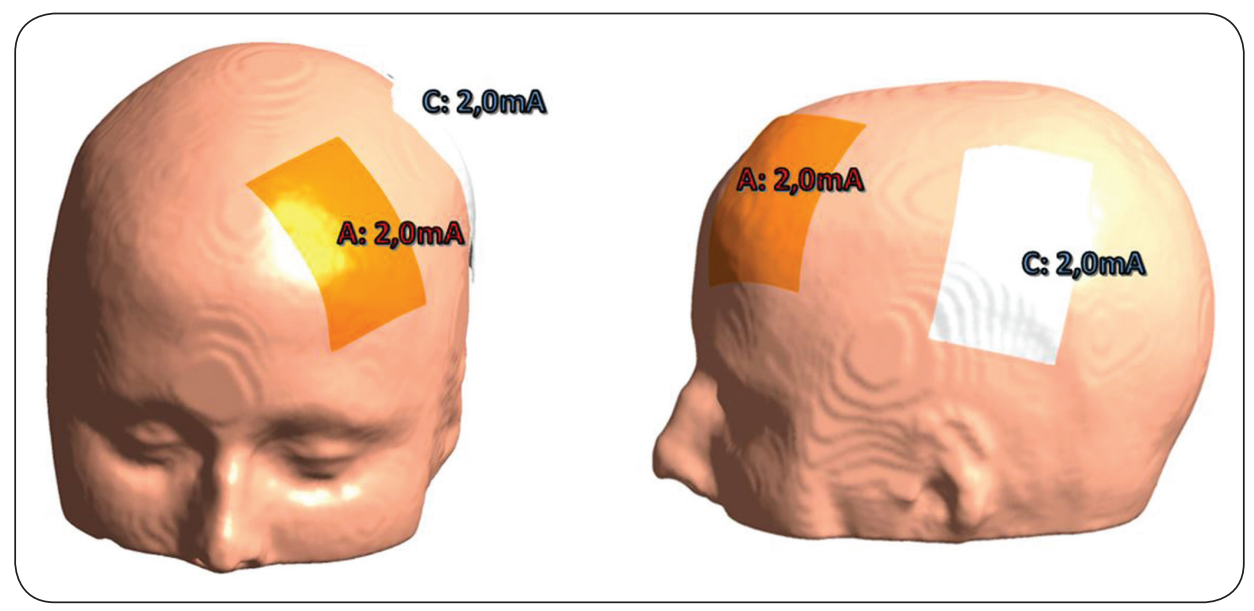

Figure 1 - Transcranial direct current stimulation (tDCS) electrode montage for the STARTS clinical trial. The orange electrode placed over the participant's left frontal region corresponds to the anode (A), and the white electrode placed over the left temporoparietal region corresponds to the cathode (C).

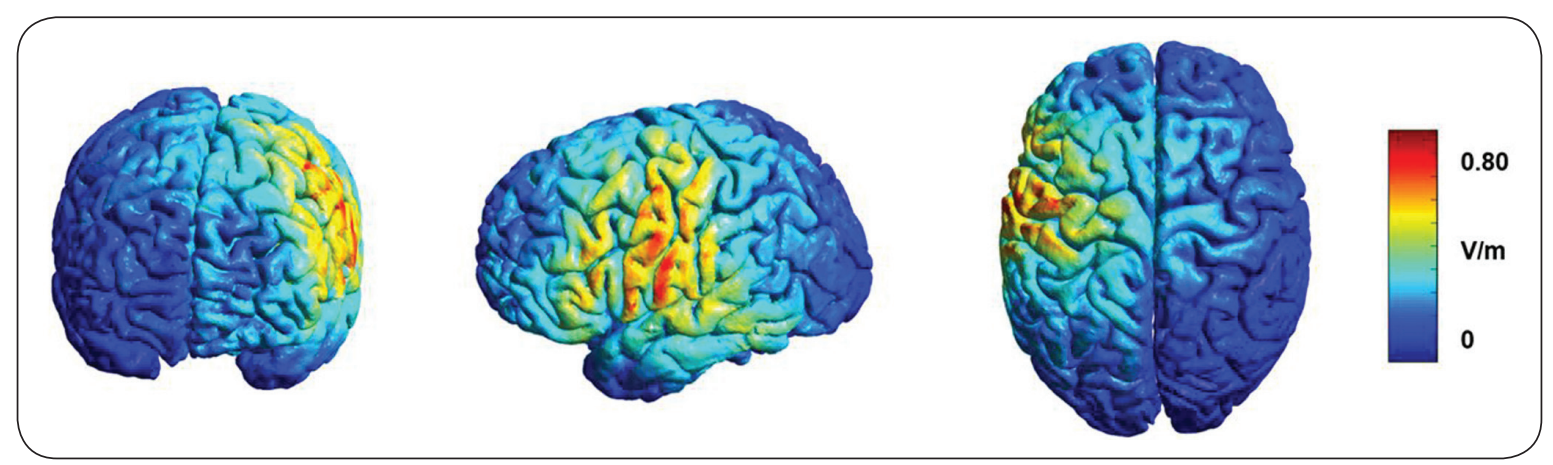

Figure $\mathbf{2}$ - Simulation of the electric field in the cortex generated by the transcranial direct current stimulation (tDCS) montage to be employed in the STARTS clinical trial. 


\section{Conclusion}

The STARTS study will investigate the efficacy of tDCS for the treatment of the negative symptoms of schizophrenia using a randomized, sham-controlled design. The biomarker investigation will contribute to the understanding of the neurobiological mechanisms of schizophrenia and their relationship with treatment. This trial will contribute valuable information to the treatment of schizophrenia.

\section{Acknowledgements}

The authors thank Coordenação de Aperfeiçoamento de Pessoal de Nível Superior (CAPES) for the financial support provided to Instituto Nacional de Biomarcadores em Neuropsiquiatria (INBioN), and the Stanley Medical Research Institute.

\section{Disclosure}

No conflicts of interest declared concerning the publication of this article.

\section{References}

1. Andreasen NC, Olsen S. Negative $v$ positive schizophrenia. Definition and validation. Arch Gen Psychiatry. 1982;39:789-94.

2. Ananth J, Djenderdjian A, Shamasunder P, Costa J, Herrera J, Sramek J. Negative symptoms: psychopathological models. J Psychiatry Neurosci. 1991;16:12-8.

3. Crow TJ. Brain changes and negative symptoms in schizophrenia. Psychopathology. 1995;28:18-21.

4. Anthony WA, Jansen MA. Predicting the vocational capacity of the chronically mentally ill. Research and policy implications. Am Psychol. 1984;39:537-44.

5. Bowen L, Wallace CJ, Glynn SM, Nuechterlein KH, Lutzker JR, Kuehnel TG. Schizophrenic individuals' cognitive functioning and performance in interpersonal interactions and skills training procedures. J Psychiatr Res. 1994;28:289-301.

6. Fenton WS, McGlashan TH. Antecedents, symptom progression, and long-term outcome of the deficit syndrome in schizophrenia. Am J Psychiatry. 1994;151:351-6.

7. Gasquet I, Haro JM, Novick D, Edgell ET, Kennedy L, Lepine JP. Pharmacological treatment and other predictors of treatment outcomes in previously untreated patients with schizophrenia: results from the European Schizophrenia Outpatient Health Outcomes (SOHO) study. Int Clin Psychopharmacol. 2005;20:199205.

8. Sarkar S, Hillner K, Velligan DI. Conceptualization and treatment of negative symptoms in schizophrenia. World J Psychiatry. 2015;5:352-61.

9. Kishimoto H, Yamada K, Iseki E, Kosaka K, Okoshi T. Brain imaging of affective disorders and schizophrenia. Psychiatry Clin Neurosci. 1998;52 Suppl:S212-4.

10. Cohen JD, Perlstein WM, Braver TS, Nystrom LE, Noll DC, Jonides J, et al. Temporal dynamics of brain activation during a working memory task. Nature. 1997;386:604-8.

11. Sabri O, Erkwoh R, Schreckenberger M, Cremerius U, Schulz G, Dickmann $C$, et al. Regional cerebral blood flow and negative/ positive symptoms in 24 drug-naive schizophrenics. J Nucl Med. $1997 ; 38: 181-8$
12. Andreasen NC, O'Leary DS, Flaum M, Nopoulos P, Watkins GL, Boles Ponto LL, et al. Hypofrontality in schizophrenia: distributed dysfunctional circuits in neuroleptic-naive patients. Lancet. 1997;349:1730-4.

13. Burt T, Lisanby $\mathrm{SH}$, Sackeim HA. Neuropsychiatric applications of transcranial magnetic stimulation: a meta analysis. Int J Neuropsychopharmacol. 2002;5:73-103.

14. Eisenegger C, Treyer V, Fehr E, Knoch D. Time-course of "off-line" prefrontal rTMS effects--a PET study. Neuroimage. 2008;42:37984.

15. Le YY, Qian GZ, Sui LM, Gong QZ, Xu RB. [Low-affinity binding sites of glucocorticoid]. Zhongguo Yao Li Xue Bao. 1991;12:35862.

16. Rollnik JD, Huber TJ, Mogk H, Siggelkow S, Kropp S, Dengler R, et al. High frequency repetitive transcranial magnetic stimulation (rTMS) of the dorsolateral prefrontal cortex in schizophrenic patients. Neuroreport. 2000;11:4013-5.

17. Sachdev P, Loo C, Mitchell P, Malhi G. Transcranial magnetic stimulation for the deficit syndrome of schizophrenia: a pilot investigation. Psychiatry Clin Neurosci. 2005;59:354-7.

18. Sommer IE, de Weijer AD, Daalman K, Neggers SF, Somers M, Kahn RS, et al. Can fMRI-guidance improve the efficacy of rTMS treatment for auditory verbal hallucinations? Schizophr Res. 2007;93:406-8.

19. Schonfeldt-Lecuona C, Gron G, Walter H, Buchler N, Wunderlich A, Spitzer M, et al. Stereotaxic rTMS for the treatment of auditory hallucinations in schizophrenia. Neuroreport. 2004;15:1669-73.

20. Poulet E, Brunelin J, Bediou B, Bation R, Forgeard L, Dalery J, et al. Slow transcranial magnetic stimulation can rapidly reduce resistant auditory hallucinations in schizophrenia. Biol Psychiatry. 2005; 57:188-91.

21. McIntosh AM, Semple D, Tasker K, Harrison LK, Owens DG, Johnstone EC, et al. Transcranial magnetic stimulation for auditory hallucinations in schizophrenia. Psychiatry Res. 2004;127:9-17.

22. Loo CK, Sainsbury K, Mitchell P, Hadzi-Pavlovic D, Sachdev PS. A sham-controlled trial of left and right temporal rTMS for the treatment of auditory hallucinations. Psychol Med. 2010;40:541-6.

23. Lee SH, Kim W, Chung YC, Jung KH, Bahk WM, Jun TY, et al. A double blind study showing that two weeks of daily repetitive TMS over the left or right temporoparietal cortex reduces symptoms in patients with schizophrenia who are having treatment-refractory auditory hallucinations. Neurosci Lett. 2005;376:177-81.

24. Hajak G, Marienhagen J, Langguth $B$, Werner $S$, Binder $H$, Eichhammer P. High-frequency repetitive transcranial magnetic stimulation in schizophrenia: a combined treatment and neuroimaging study. Psychol Med. 2004;34:1157-63.

25. Blumberger DM, Fitzgerald PB, Mulsant BH, Daskalakis ZJ. Repetitive transcranial magnetic stimulation for refractory symptoms in schizophrenia. Curr Opin Psychiatry. 2010;23:8590.

26. Cohen E, Bernardo M, Masana J, Arrufat FJ, Navarro V, Valls S, et al. Repetitive transcranial magnetic stimulation in the treatment of chronic negative schizophrenia: a pilot study. J Neurol Neurosurg Psychiatry. 1999;67:129-30.

27. Slotema CW, Blom JD, Hoek HW, Sommer IE. Should we expand the toolbox of psychiatric treatment methods to include Repetitive Transcranial Magnetic Stimulation (rTMS)? A meta-analysis of the efficacy of rTMS in psychiatric disorders. J Clin Psychiatry. 2010;71:873-84.

28. Dlabac-de Lange JJ, Knegtering $R$, Aleman A. Repetitive transcranial magnetic stimulation for negative symptoms of schizophrenia: review and meta-analysis. J Clin Psychiatry. 2010;71:411-8.

29. Fregni F, Pascual-Leone A. Technology insight: noninvasive brain stimulation in neurology-perspectives on the therapeutic potential of rTMS and tDCS. Nat Clin Pract Neurol. 2007;3:383-93.

30. Nitsche MA, Boggio PS, Fregni F, Pascual-Leone A. Treatment of depression with transcranial direct current stimulation (tDCS): a review. Exp Neurol. 2009;219:14-9.

31. Boggio PS, Rigonatti SP, Ribeiro RB, Myczkowski ML, Nitsche MA Pascual-Leone A, et al. A randomized, double-blind clinical trial on the efficacy of cortical direct current stimulation for the treatment of major depression. Int ] Neuropsychopharmacol. 2008;11:24954.

32. Lefaucheur JP, Antal A, Ayache SS, Benninger DH, Brunelin J, Cogiamanian F, et al. Evidence-based guidelines on the therapeutic use of transcranial direct current stimulation (tDCS). Clin Neurophysiol. 2017;128:56-92. 
33. Miranda PC, Lomarev M, Hallett M. Modeling the current distribution during transcranial direct current stimulation. Clinical neurophysiology : official journal of the International Federation of Clinical Neurophysiology. 2006;117:1623-9.

34. Wagner T, Fregni F, Fecteau S, Grodzinsky A, Zahn M, PascualLeone A. Transcranial direct current stimulation: a computerbased human model study. Neuroimage. 2007;35:1113-24.

35. Bindman LJ, Lippold OC, Redfearn JW. The Action of Brief Polarizing Currents on the Cerebral Cortex of the Rat (1) during Current Flow and (2) in the Production of Long-Lasting afterEffects. J Physiol. 1964;172:369-82.

36. Priori A, Hallett M, Rothwell JC. Repetitive transcranial magnetic stimulation or transcranial direct current stimulation? Brain Stimul. 2009;2:241-5.

37. Brunelin J, Mondino M, Gassab L, Haesebaert F, Gaha L, SuaudChagny MF, et al. Examining transcranial direct-current stimulation (tDCS) as a treatment for hallucinations in schizophrenia. Am J Psychiatry. 2012;169:719-24.

38. Lewis SW, Barnes TR, Davies L, Murray RM, Dunn G, Hayhurst $\mathrm{KP}$, et al. Randomized controlled trial of effect of prescription of clozapine versus other second-generation antipsychotic drugs in resistant schizophrenia. Schizophr Bull. 2006;32:715-23.

39. Brunoni AR, Amadera J, Berbel B, Volz MS, Rizzerio BG, Fregni F. A systematic review on reporting and assessment of adverse effects associated with transcranial direct current stimulation. The International Journal of Neuropsychopharmacology. 2011; 14:1133-45

40. Gandiga PC, Hummel FC, Cohen LG. Transcranial DC stimulation (tDCS): a tool for double-blind sham-controlled clinical studies in brain stimulation. Clinical neurophysiology : official journal of the International Federation of Clinical Neurophysiology. 2006;117:845-50.

41. Gandiga PC, Hummel FC, Cohen LG. Transcranial DC stimulation (tDCS): a tool for double-blind sham-controlled clinical studies in brain stimulation. Clin Neurophysiol. 2006;117:845-50.

42. Cordes J, Thunker J, Agelink MW, Arends M, Mobascher A, Wobrock $\mathrm{T}$, et al. Effects of $10 \mathrm{~Hz}$ repetitive transcranial magnetic stimulation (rTMS) on clinical global impression in chronic schizophrenia. Psychiatry Res. 2010;177:32-6.

43. Gur RC, Richard J, Hughett $P$, Calkins ME, Macy L, Bilker WB, et al. A cognitive neuroscience-based computerized battery for efficient measurement of individual differences: standardization and initial construct validation. J Neurosci Methods. 2010;187:254-62.

44. Nieto $R$, Kukuljan $M$, Silva $H$. BDNF and schizophrenia: from neurodevelopment to neuronal plasticity, learning, and memory. Front Psychiatry. 2013;4:45.

45. Rybakowski JK, Borkowska A, Skibinska M, Szczepankiewicz A Kapelski P, Leszczynska-Rodziewicz A, et al. Prefrontal cognition in schizophrenia and bipolar illness in relation to Val66Met polymorphism of the brain-derived neurotrophic factor gene. Psychiatry Clin Neurosci. 2006;60:70-6.

46. Grillo RW, Ottoni GL, Leke R, Souza DO, Portela LV, Lara DR. Reduced serum BDNF levels in schizophrenic patients on clozapine or typical antipsychotics. J Psychiatr Res. 2007;41:31-5.

47. Tan YL, Zhou DF, Cao LY, Zou YZ, Zhang XY. Decreased BDNF in serum of patients with chronic schizophrenia on long-term treatment with antipsychotics. Neurosci Lett. 2005;382:27-32.

48. Fernandes BS, Steiner J, Berk M, Molendijk ML, Gonzalez-Pinto $A$, Turck CW, et al. Peripheral brain-derived neurotrophic factor in schizophrenia and the role of antipsychotics: meta-analysis and implications. Mol Psychiatry. 2015;20:1108-19.

49. Palomino A, Vallejo-Illarramendi A, González-Pinto A, Aldama A, González-Gómez C, Mosquera F, et al. Decreased levels of plasma BDNF in first-episode schizophrenia and bipolar disorder patients. Schizophr Res. 2006;86:321-2.

50. Radhu N, de Jesus DR, Ravindran LN, Zanjani A, Fitzgerald PB, Daskalakis ZJ. A meta-analysis of cortical inhibition and excitability using transcranial magnetic stimulation in psychiatric disorders. Clin Neurophysiol. 2013;124:1309-20.

51. Chen R, Cros D, Curra A, Di Lazzaro V, Lefaucheur JP, Magistris $M R$, et al. The clinical diagnostic utility of transcranial magnetic stimulation: report of an IFCN committee. Clin Neurophysiol. 2008; 119:504-32

52. Harrison PJ. Recent genetic findings in schizophrenia and their therapeutic relevance. J Psychopharmacol. 2015;29:85-96.

53. Windhoff M, Opitz A, Thielscher A. Electric field calculations in brain stimulation based on finite elements: an optimized processing pipeline for the generation and usage of accurate individual head models. Hum Brain Mapp. 2013;34:923-35.

54. Saturnino GB, Antunes A, Thielscher A. On the importance of electrode parameters for shaping electric field patterns generated by tDCS. Neuroimage. 2015;120:25-35.

55. Brunoni AR, Shiozawa $P$, Truong $D$, Javitt DC, Elkis $H$, Fregni $F_{\text {, }}$ et al. Understanding tDCS effects in schizophrenia: a systematic review of clinical data and an integrated computation modeling analysis. Expert Rev Med Devices. 2014;11:383-94.

56. Brunelin J, Mondino M, Gassab L, Haesebaert F, Gaha L, SuaudChagny MF, et al. Examining transcranial direct-current stimulation (tDCS) as a treatment for hallucinations in schizophrenia. Am J Psychiatry. 2012;169:719-24.

\section{Correspondence:}

Leandro Valiengo

Al. Ministro Rocha Azevedo, 882/22

01410-002 - São Paulo, SP - Brazil

Tel.: +55 (11) 38810110

E-mail: valiengo@usp.br 